\title{
Cryptocephaline Egg Case Provides Incomplete Protection from Generalist Predators (Coleoptera: Chrysomelidae)
}

\author{
Matthias Schöller \\ Faculty of Life Sciences, Humboldt-Universität zu Berlin, Lentzeallee 55/57, 14195 Berlin, Germany \\ Correspondence should be addressed to Matthias Schöller; matthias.schoeller@hu-berlin.de
}

Received 14 September 2014; Accepted 15 December 2014; Published 30 December 2014

Academic Editor: Jan Klimaszewski

Copyright ( 2014 Matthias Schöller. This is an open access article distributed under the Creative Commons Attribution License, which permits unrestricted use, distribution, and reproduction in any medium, provided the original work is properly cited.

\begin{abstract}
The egg case of Cryptocephalus rufipes (Goeze) is described and illustrated. In laboratory trials, eggs of field-collected C. rufipes were observed for larval emergence (untreated control) or exposed to two species of generalist predators, Chrysoperla carnea (Stephens) or Xylocoris flavipes (Reuter) in no-choice experiments. The behaviour of the predators upon contact with the C. rufipes eggs was observed. The number of hatching larvae was counted and compared. In the presence of each of the two species of predators, larval emergence was significantly reduced. Eggs that were not protected by an egg case were completely consumed by the predators. C. rufipes eggs were therefore incompletely protected from the studied generalist predators. This is the first study showing experimentally the protective function of cryptocephaline egg case.
\end{abstract}

\section{Introduction}

Leaf beetles in the subfamilies Cryptocephalinae and Lamprosomatinae cover their eggs with small faecal plates. These faecal plates compose a solid egg case that is completely covering the egg. After hatching, the larva is biting a hole in the egg case, and it is wearing it as a larval case. This larval case is continuously enlarged with larval faeces when the larva is moulting and growing [1-3]. One of the functions of the egg and larval cases is thought to be protection from natural enemies $[4,5]$. However, both mammal and insect predators and hymenopterous parasitoids are known to accept cryptocephaline larvae as prey or host, respectively $[1,4-9]$. First-instar larvae that are still in their egg cases, but not eggs of Clytra laeviuscula and C. quadripunctata, were observed to be picked up and transported by ants [10]. However, the larvae of these Clytra species are known to live inside the nests of ants [11, 12]; consequently the ants are not expected to prey upon the eggs. While some information on natural enemies of larvae accumulated, nothing seems to be known about natural enemies of cryptocephaline eggs. One of the reasons of this gap in knowledge may be the difficulty to find eggs in nature. Some species attach their egg with the help of a stalk to the host plant $[13,14]$, where they can be observed in the field. However, the eggs of most species drop to the ground after the female finished building the egg case [3], and then the eggs are difficult to find and observe among the leaf litter. To overcome this problem, in this study adult Cryptocephalus (Burlinius) rufipes (Goeze, 1777) were held in a rearing container, the eggs collected and exposed to two different species of laboratory-reared generalist predators, the common green lacewing Chrysoperla carnea (Stephens, 1836) (Neuroptera, Chrysopidae) and the warehouse pirate bug Xylocoris flavipes (Reuter, 1875) (Heteroptera, Anthocoridae). Moreover, the egg cases of C. rufipes are redescribed and illustrated. C. rufipes is widely distributed in Europe, from Portugal to Turkey, and in Northern Africa [15]. In urban areas, it was found feeding on its host plant Salix purpurea Linnaeus, 1753, which is planted as a park tree or to form hedges.

\section{Materials and Methods}

Adult males and females of C. rufipes were collected from Salix purpurea in Berlin, Friedrichshain $\left(52^{\circ} 52.3272^{\prime} \mathrm{N}\right.$, $\left.13^{\circ} 46.5825^{\prime} \mathrm{E}\right)$, in June and July, 2014. The adults were kept in $250 \mathrm{~mL}$ glass-jars covered with pieces of clothing held with rubber bands at $23 \pm 2^{\circ} \mathrm{C}$ and $60 \pm 5 \% \mathrm{RH}$. The bottom of the jar was lined with filter paper. A twig of the host 


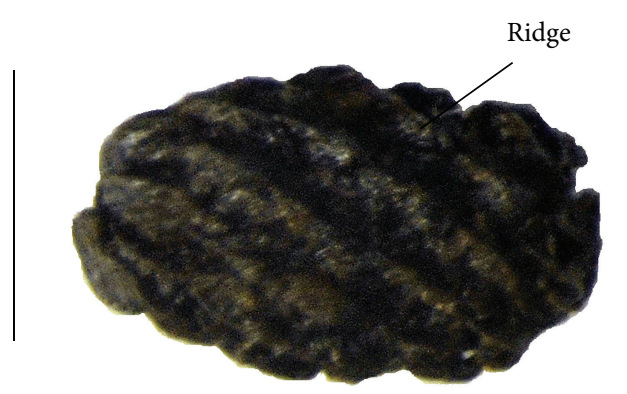

FIgURE 1: Egg of Cryptocephalus rufipes (Goeze, 1777), scale = $0.5 \mathrm{~mm}$.

plant $S$. purpurea was placed in a narrow plastic tube $(5 \times$ $1.2 \mathrm{~cm}$ ) filled with water and closed with a plug of paper towel to prevent the water from loss by leakage. The twig was replaced when necessary. Eggs laid by several females were collected daily from the bottom of the jars. The eggs were transferred to Petri-dishes (diameter: $5 \mathrm{~cm}$ ) lined with paper. To each Petri-dish, five $C$. rufipes eggs and either two adult $X$. flavipes, two larvae of $C$. carnea, or no predators (untreated control) were added. Each treatment had 11 replications. The behaviour of the predators upon first contact with the $C$. rufipes-eggs was observed. In the first three days after adding the predators, the experiments were controlled for survival of the predators. After seven days, eggs were controlled daily for larval emergence. Additionally, five Petri-dishes were prepared with five eggs of Ephestia kuehniella each and either two adult $X$. flavipes, two larvae of $C$. carnea, or no predators (untreated control). Laboratory-reared larvae of C. carnea and adults of $X$. flavipes were obtained from Biologische Beratung Ltd., Berlin.

The results were analysed with the help of SigmaStat 3.1 software. The number of leaf beetle larvae emerged was subjected to a Kruskal-Wallis One Way Analysis of Variance on Ranks followed by All Pairwise Multiple Comparison Procedures, Dunn's Method, to separate means. Treatments were considered significantly different at the $P=0.05$ level. Percentage natural mortality data of $C$. rufipes eggs were not corrected for control mortality, because mortality in the untreated control treatment was $<5 \%$. The size of 30 eggs, that is, length and width in lateral view, was measured with a measuring ocular mounted on a dissecting microscope.

\section{Results}

3.1. Field Observations. Beside C. rufipes, several other Chrysomelidae were occurring on Salix purpurea in June and July, namely Cryptocephalus (Burlinius) ocellatus ocellatus Drapiez, 1819, C. androgyne Marseul, 1857, Phratora vitellinae (Linnaeus, 1758), and Clytra laeviuscula (Ratzeburg, 1837). Moreover, the weevil Polydrusus (Polydrusus) picus (Fabricius, 1792) was found feeding and mating on S. purpurea.

3.2. Morphology of C. rufipes Eggs. The eggs of C. rufipes are blackish to greyish brown with eight narrow, regular ridges as illustrated in Figure 1. Each individual faecal plate

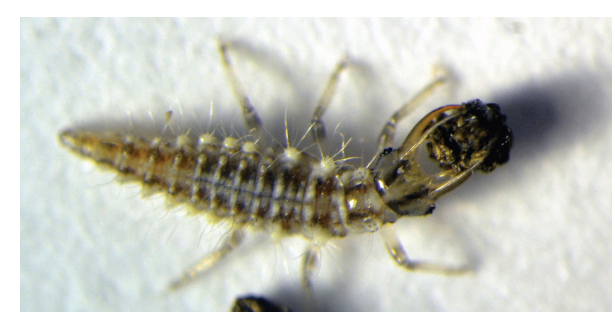

Figure 2: Larva of Chrysoperla carnea (Stephens, 1836) uplifting an egg of Cryptocephalus rufipes (Goeze, 1777).

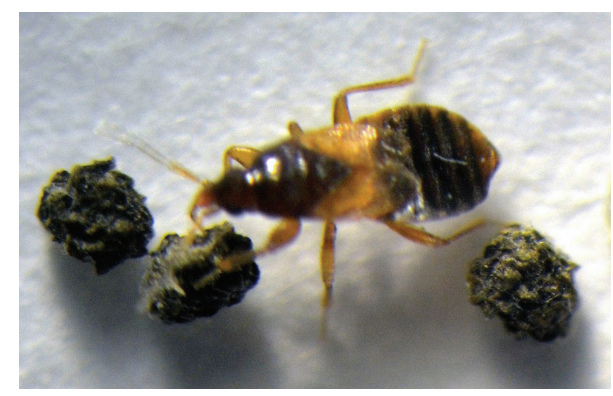

FIGURE 3: Adult of Xylocoris flavipes (Reuter, 1875) handling an egg of Cryptocephalus rufipes (Goeze, 1777).

bears a little crest; the regular arrangement of the faecal plates composes the ridges that have little gaps in case the faecal plates do not perfectly touch. The mean size $\pm \mathrm{SD}$ was $0.797 \mathrm{~mm} \pm 0.057 \mathrm{~mm}$ length and $0.532 \mathrm{~mm} \pm 0.033 \mathrm{~mm}$ width; median was 0.80 for length and 0.53 for width. Length was ranging from 0.700 to $0.975 \mathrm{~mm}$, width from 0.475 to $0.600 \mathrm{~mm}$. The eggs are elongate oval; the mean length to width ratio was $1.50 \mathrm{~mm} \pm 0.095$, ranging from 1.25 to 1.70 (median 1.50).

3.3. Experiments with Eggs of E. kuehniella. The experiments with eggs of E. kuehniella resulted in complete predation of these eggs by both $C$. carnea and $X$. flavipes. In the untreated control, $92 \%$ of the E. kuehniella-eggs emerged.

3.4. Experiments with Eggs of C. rufipes, Behavioural Observations. When encountering the C. rufipes eggs, the larvae of C. carnea showed the typical prey uplifting behaviour. They fixed the C. rufipes eggs and held them in position (Figure 2). $X$. flavipes examined the eggs after contacting it (Figure 3 ). Within the first three days of the experiment, in all trials one predator consumed the second; consequently, cannibalism occurred.

3.5. Experiments with Eggs of C. rufipes, Larval Hatch. Larvae hatched after 10 to 13 days. The presence of the predators significantly affected the number of hatching C. rufipeslarvae from the eggs (Kruskal-Wallis One Way Analysis of Variance on Ranks, $H=18.473, \mathrm{DF}=2, P<0.001)$. In the untreated control, a mean \pm SD of $3.23 \pm 1.02$ larvae hatched. The presence of both $C$. carnea and $X$. flavipes significantly reduced the number of hatching C. rufipes-eggs (All Pairwise 


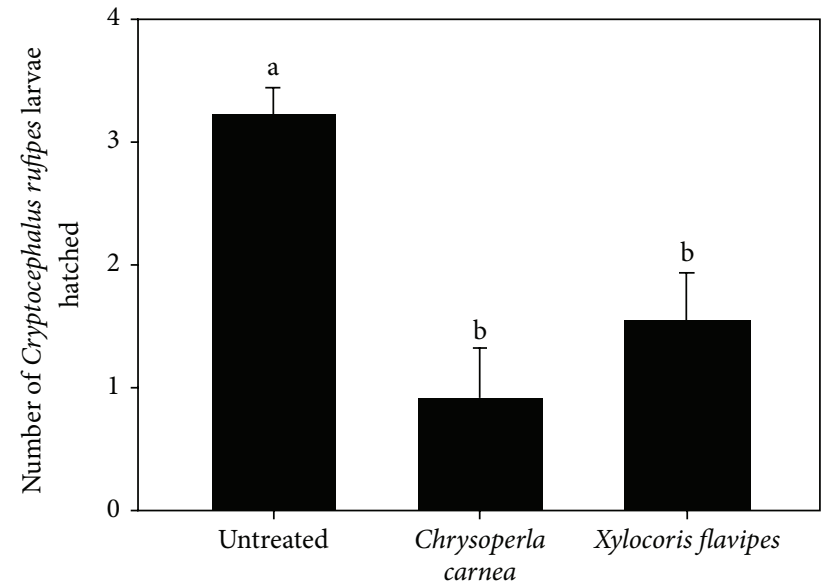

FIGURE 4: Number of Cryptocephalus rufipes-larvae hatched out of five eggs exposed to Chrysoperla carnea or Xylocoris flavipes, or no predators (untreated). Means followed by the same lowercase letter do not differ significantly at $P<0.05$ (Dunn's Method) $(n=11)$.

Multiple Comparison Procedures, Dunn's Method, $Q=3.891$ and 2.817, $P<0.05)$. A mean of $0.91 \pm 1.38$ and $1.55 \pm$ 1.29 hatched in the presence of $C$. carnea and $X$. flavipes, respectively. However, there was no statistical difference in reduction between the two predators (Dunn's Method, $Q=$ $0.929, P>0.05$ ) (Figure 4).

\section{Discussion}

The egg of C. rufipes was first described in 1852 [1], under two synonyms, that is, C. gracilis Fabricius, 1792, and C. minutus Fabricius, 1792. An egg length of $0.75 \mathrm{~mm}$ as well as a surface with eight to nine ridges was given. For C. gracilis, regular ridges and a blackish green colour were described, and for C. minutus irregular ridges and a yellowish green colour. The egg of C. minutus was figured [1, Figure 18]: the egg in this figure is less elongate and the ridges are wider compared to the eggs described in the present study. In 1899, again the egg case was described twice under C. gracilis and C. minutus, possibly mixing information from [1] and own observations [16]. For the eggs described under C. minutus [16, page 51], a length ranging from 0.7 to 0.8 was given, data in accordance with those found in the present study. However, the eggs were described as yellowish grey with slightly irregular ridges, contrary to the blackish brown eggs with rather regular ridges described here. For the eggs described under C. gracilis [16, page 56], a short note was given stating a length of $0.8 \mathrm{~mm}$, a surface with nine narrow bend carinae and a greyish colour, fitting better to the eggs described here. However, as the determination of species in the subgenus Burlinius Lopatin, 1965 , requires in many cases the study of aedeagus characters [17], the identity of immatures described in the 19th Century remains sometimes doubtful, and especially the immatures described as $C$. minutus probably belong to another species. Even though the shape of the eggs is variable as indicated by the range of the length to width ratio, they can be, for example, easily distinguished from those of the related synoekous species $C$. ocellatus, which are yellowish brown with blunt ridges.

Concerning natural enemies of C. rufipes, reports are available about larval parasitoids $[1,16]$. No information was traced on natural enemies of eggs of Cryptocephalinae in general.

In the laboratory trials, feeding could not be directly observed, as both species of predators have piercing-sucking moth parts. However, the behavioural observations indicated the predators identified the C. rufipes eggs as prey items. The trials with the E. kuehniella eggs showed the ability of the predators to locate the eggs within the experimental arena, and that food was a limiting factor for survival in these no-choice experiments. At least after cannibalism, the predators relied upon the eggs of C. rufipes for survival. The analysis of $C$. rufipes hatching showed a significant reduction of larval emergence in the presence of both predators, proving indirectly the predator-induced mortality. However, contrary to the experiments with the eggs of E. kuehniella, predation of C. rufipes eggs was not complete. This observation suggests egg cases of $C$. rufipes provide a protection against predation by generalist predators, although incomplete.

Larvae of C. carnea are known to prey on eggs of various insects [18]. Both adults and larvae of $X$. flavipes are known to prey on insect eggs, including eggs of Chrysomelidae [19]. Both C. carnea and related species and anthocorid predators commonly occur in Central Europe. However, they may not frequently encounter $C$. rufipes eggs in the leaf litter because they are typically foraging on leafs. C. carnea and X. flavipes were used here as model organisms for generalist predators with piercing-sucking mouth parts. Possibly the egg cases provide even better protection against small predators with chewing mouth parts. Natural enemies of cryptocephaline eggs in biotic communities have to be identified and studied in future field studies.

\section{Conflict of Interests}

The author declares that there is no conflict of interests regarding the publication of this paper.

\section{References}

[1] W. G. Rosenhauer, Über die Entwicklung und Fortpflanzung der Clythren und Cryptocephalen, einer Insektengruppe aus der Ordnung der Coleoptera [Ph.D. thesis], Philosophische Fakultät Universität Erlangen, J. J. Barfuß’sche UniversitätsBuchdruckerei, Erlangen, Germany, 1852.

[2] D. Erber, "Beitrag zur Entwicklungsbiologie mitteleuropäischer Clytrinen und Cryptocephalinen (Coleoptera, Chrysomelidae)," in Zoologische Jahrbücher, vol. 96, pp. 453-477, Abteilung für Systematik Ökologie und Geographie der Tiere, 1969.

[3] D. Erber, "Biology of Camptostomata Clytrinae-Cryptocephalinae-Chlamisinae-Lamprostomatinae," in Biology of Chrysomelidae, P. H. Jolivet, E. Petitpierre, and T. H. Hsiao, Eds., pp. 513-552, Kluwer Academic Publishers, Dordrecht, The Netherlands, 1988.

[4] J. B. Wallace, "The defensive function of a case on a chrysomelid larva," Journal of the Georgia Entomological Society, vol. 5, no. 1, pp. 19-24, 1970. 
[5] C. G. Brown and D. J. Funk, "Antipredatory properties of an animal architecture: how complex faecal cases thwart arthropod attack," Animal Behaviour, vol. 79, no. 1, pp. 127-136, 2010.

[6] M. L. Cox, "The hymenoptera and diptera parasitoids of chrysomelidae," in Novel Aspects of the Biology of Chrysomelidae, P. H. Jolivet, M. L. Cox, and E. Petitpierre, Eds., pp. 582-590, Kluwer Academic Publishers Series Entomologica, Dordrecht, Netherlands, 1994.

[7] M. L. Cox, "Insect predators of Chrysomelidae," in Chrysomelidae Biology: Ecological Studies, P. H. A. Jolivet and M. L. Cox, Eds., pp. 23-91, SPB Academic, Amsterdam, Netherlands, 1996.

[8] M. Schöller, "Field studies of Cryptocephalinae biology," in Advances in Chrysomelidae Biology, M. L. Cox, Ed., vol. 1, pp. 421-436, Backhuys, Leiden, The Netherlands, 1999.

[9] J. A. Owen, "Field studies on Cryptocephalus coryli (Linnaeus) (Coleoptera: Chrysomelidae)," Entomologist's Gazette, vol. 54, no. 1, pp. 39-44, 2003.

[10] M. Schöller, "Larvae of case-bearing leaf beetles (Coleoptera: Chrysomelidae: Cryptocephalinae)," Acta Entomologica Musei Nationalis Pragae, vol. 51, no. 2, pp. 747-748, 2011.

[11] W. G. Rosenhauer, "Über die Larve der Clythra 4punctata," in Stettiner Entomologische Zeitung, vol. 1842 of Entomologische Mittheilungen 6, pp. 50-52, 1842.

[12] E. Skwarra, "Über die Ernährungsweise der Larven von Clytra quadripunctata," Zoologischer Anzeiger, vol. 50, pp. 83-96, 1927.

[13] M. Schöller and U. Heinig, "The species of Acolastus Gerstaecker, 1855 of Israel and Sinai with identification key, and description of larva and egg of Acolastus hebraeus (J. Sahlberg) (Coleoptera: Chrysomelidae: Cryptocephalinae)," Entomologische Zeitschrift, vol. 116, pp. 83-90, 2006.

[14] M. Wassowska, "Morphology of the first instar larva and of the egg of Labidostomis longimana (Linnaeus, 1761) and of Labidostomis tridentata (Linnaeus, 1758) (Coleoptera, Chrysomelidae, Clytrinae), with a key to clytrine genera with the first instar larva known," Deutsche Entomologische Zeitschrift, vol. 54, no. 1, pp. 51-67, 2007.

[15] I. Lopatin, A. Smetana, and M. Schöller, "Tribe Cryptocephalini Gyllenhal, 1813, genus Cryptocephalus Geoffroy, 1762," in Catalogue of Palaearctic Coleoptera, Volume 6, Chrysomeloidea, I. Löbl and A. Smetana, Eds., pp. 580-606, Apollo Books, Stenstrup, Denmark, 2010.

[16] P. J. V. Xambeu, "Moeurs et métamorphoses des Insectes," Annales de la Société Linnéenne de Lyon, vol. 45, pp. 1-72, 1899.

[17] A. Warchałowski, The Palaearctic Chrysomelidae, Identification Keys, vol. 1, Natura Optima dux Foundation, Warsaw, Poland, 2010.

[18] G. Shrestha and A. Enkegaard, "The green lacewing, Chrysoperla carnea: preference between lettuce aphids, Nasonovia ribisnigri, and western flower thrips, Frankliniella occidentalis," Journal of Insect Science, vol. 13, article 94, 2013.

[19] S. E. Sing and R. T. Arbogast, "Predatory response of Xylocoris flavipes to bruchid pests of stored food legumes," Entomologia Experimentalis et Applicata, vol. 126, no. 2, pp. 107-114, 2008. 

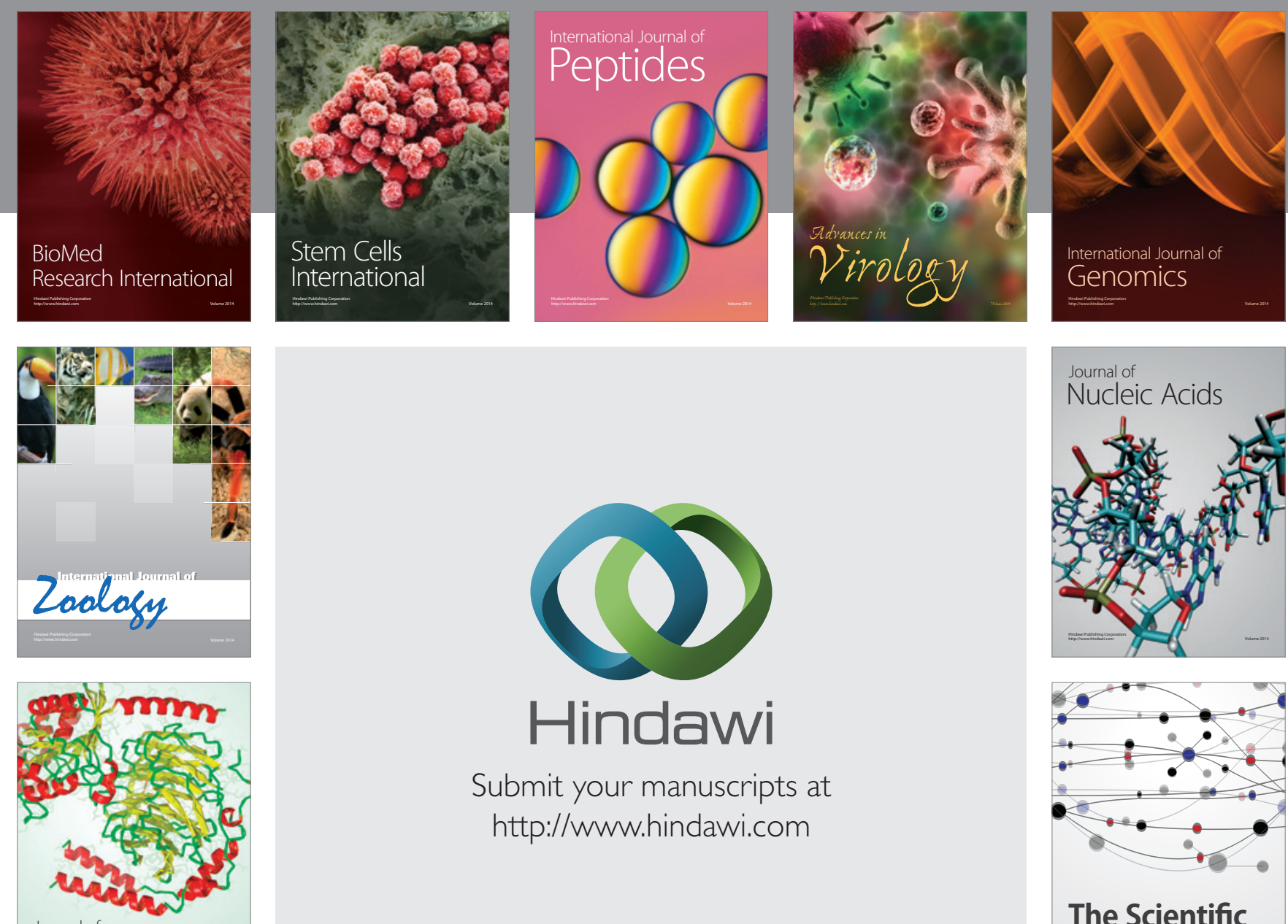

Submit your manuscripts at

http://www.hindawi.com

Journal of
Signal Transduction
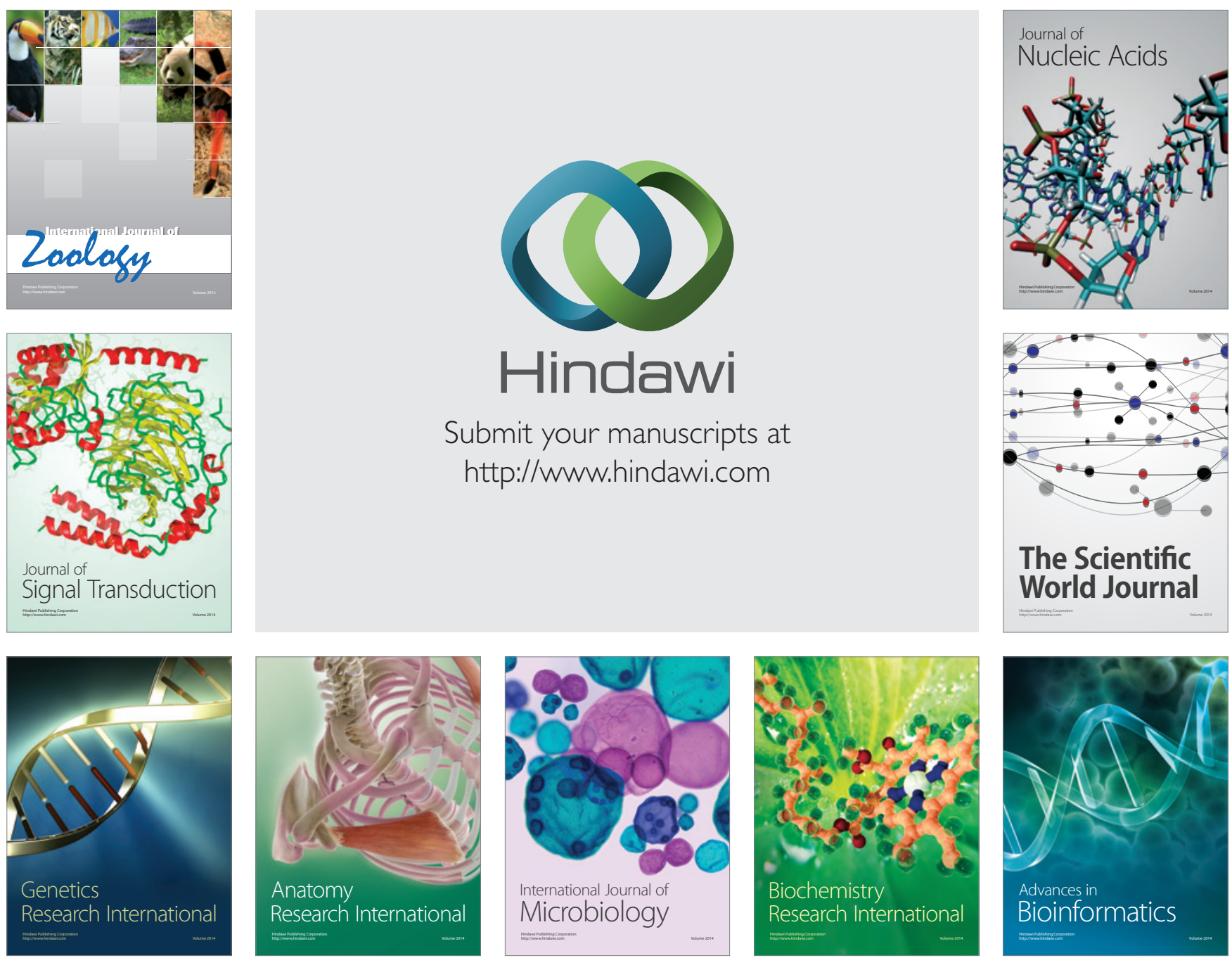

The Scientific World Journal
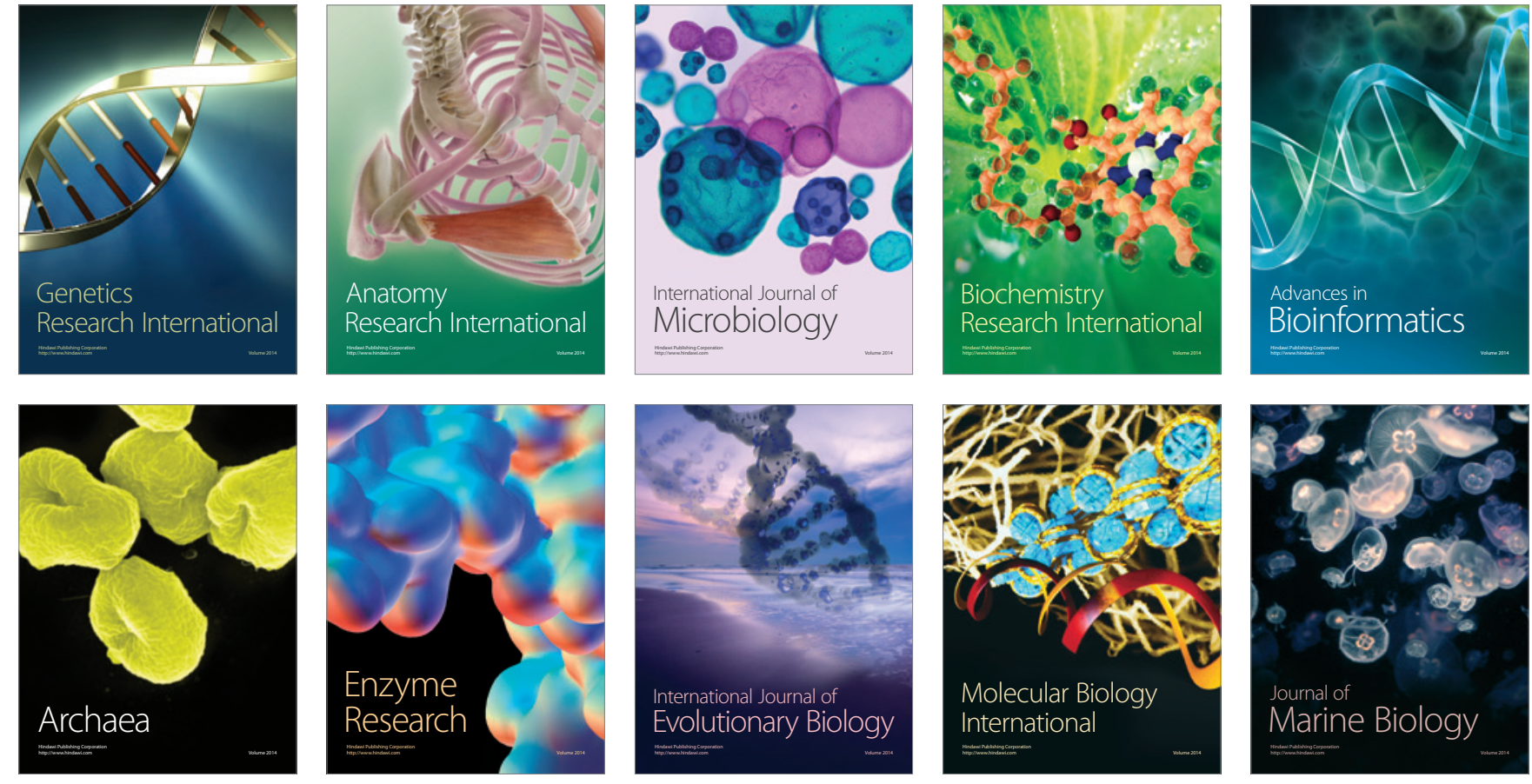